Article

\title{
Wireless Monitoring of Induction Machine Rotor Physical Variables
}

\author{
Jefferson Doolan Fernandes ${ }^{2}$, Francisco Elvis Carvalho Souza ${ }^{1}$, Glauco George Cipriano \\ Maniçoba ${ }^{1, *}$, Andres Ortiz Salazar ${ }^{1,2}$ and José Alvaro de Paiva ${ }^{3}$. \\ 1 Programa de Pós-graduação em Engenharia Elétrica, Universidade Federal do Rio Grande do Norte, \\ Campus Universitário Lagoa Nova, Centro de Tecnologia, Natal, RN. \\ 2 Programa de Pós- Graduação em Ciência e Engenharia de Petróleo, Universidade Federal do Rio Grande do \\ Norte, Campus Universitário,Lagoa Nova, Centro de Ciências Exatas e da Terra, Natal, RN. \\ 3 Instituto Federal de Educação, Ciência e Tecnologia do Rio Grande do Norte, Campus Ceará Mirim, Ceará \\ Mirim, RN. \\ * Correspondence: glaucogeorge@yahoo.com.br; Tel.: +55-084-99100-3581
}

\begin{abstract}
With the widespread use of electric machines there is a growing need to extract information from the machines to optimize their control systems and maintenance management. The present work shows the development of an embedded system to perform the monitoring of an squirrel cage induction motor rotor physical variables. The system comprises: circuit to acquire desirable rotor variable(s) value(s) and send it to the computer; a rectifier and power storage circuit that besides converting an alternating current in continuous also store energy for a certain amount of time to wait the motor engine shutdown; and magnetic generator that harvest energy from rotating field to power the circuits mentioned above. The embedded system is set on the rotor, making it difficult to power the system because it is rotating, problem solved with the construction of the magnetic generator eliminating the need of using batteries or collector rings and send data to the computer using a wireless NRF24L01 module. For the proposed system validation a temperature sensor (DS18b20) was used, variable known as the most important when identifying the need for maintenance and control systems. Tests were made getting satisfactory results proving the viability of using sensors on the rotor.
\end{abstract}

Keywords: wireless communication, energy harvesting, electrical machines maintenance, induction motor control systems, rotor temperature.

\section{Introduction}

Electric machines play an extremely important role in the industry, many of them making up $100 \%$ of their driving power. Misuse, failure to manage maintenance, and late detection of defects can cause months of repair and result in actual production losses or overspending with replacements [1].

By monitoring the physical variables of the electrical machines it is possible to perform a more efficient and more reliable maintenance. This requires the use of suitable apparatus capable of recording various phenomena, such as: vibrations, temperature, performance, acceleration, among others. Based on the knowledge and analysis of the phenomena, it is possible to indicate, in advance, any defects or failures in the machines and equipment [9][23].

It is relatively easy to measure variables in the stationary part of the motor (stator), the difficulty appears when you want to observe the phenomena that occur in the rotor. For this, one makes use of estimations from the variables of the stator or sensors are used in the rotor, which brings great challenges due to the rotation [15] [20] [24]. 
The monitoring of rotor physical variables is very important for fault detection as well as in control systems application. In high-performance induction motors, for example, rotor temperature is a parameter present in its control algorithm, but due to the complexity of implementation and high cost to place sensors in the rotor, methods of parameter estimation are more commonly used to obtain values close to the real [24].

\subsection{Control System Application}

Of the various control techniques available in the literature, field-orientation control (FOC) is one of the most commonly used. This technique enables a decoupling between torque and flow in the alternating current machine, similar to that occurring in the DC machine with independent excitation [5] [8] [29].

The orientation according to the flow of the rotor consists on locking the daxis of the dq coordinate system with the flow of the rotor. Therefore, the quadrature component $\left(\phi_{r q}=0\right)$ is not available and the rotor flux is the $\mathrm{d}$ axis component itself:

$$
\overrightarrow{\phi_{r d q}}=\phi_{r d}=\phi_{r}
$$

Expressing the mathematical model equations of the machine as a function of the spatial vectors rotor flux and stator current and doing mathematical manipulations, the following equations are achieved [8]:

$$
\begin{aligned}
& \frac{d \phi_{r}}{d t}+\frac{1}{\tau_{r}} \phi_{r}=\frac{L_{m}}{\tau_{r}} i_{s d} \\
& T_{e m}=\frac{3}{4} p \frac{L_{m}}{L_{r}} \phi_{r} i_{s q}
\end{aligned}
$$

Where $\phi$ is the rotor flux; $\mathrm{Lm}$ is the inductance of magnetization; $\tau \mathrm{r}$ is the rotor time constant, which can be calculated by $\tau_{r}=L_{r} / R_{r}$, where $L_{r}$ is the proper inductance of the rotor and $R_{r}$ is the electrical resistance of the rotor; $i_{s d}$ and $i_{s q}$ are respectively the direct and quadrature axis components of the stator current, Tem is the electromagnetic torque developed and $\mathrm{p}$ is the number of pole pairs.

It is observed in equations (2) and (3) that the flow of the rotor is only function of isd, whereas if the flux remains constant the electromagnetic torque depends only on isq. This characterizes a decoupling in the control of the flow in relation to the control of the conjugate.

The mechanical equation is given by:

$$
J \frac{d \omega_{m}}{d t}=T_{e m}-T_{l}
$$

Where $\mathrm{J}$ is the moment of inertia of the rotor, $T_{l}$ is the load torque and $\omega_{\mathrm{m}}$ is the mechanical angular velocity of the rotor.

Thus, equations (2), (3) and (4) form the mathematical model for the induction motor fed by a current source inverter.

The determination of the spatial position of the rotor flow is essential for the implementation of control by rotor flow orientation.

One way to determine this position is by using the equation:

$$
\delta_{r}=\int_{0}^{t} p \omega_{m}(\tau) d \tau+\int_{0}^{t} \omega_{2}(\tau) d \tau
$$

The $\omega_{2}$ is the slip frequency that can be calculated by [8]:

$$
\omega_{2}=\frac{1}{\tau_{r}} \frac{I_{s q}^{*}}{I_{s d}^{*}}
$$

Where, $I^{*}$ sd and $I_{s q}^{*}$ are the reference values for the components of the stator current.

At this point it is possible to see that both the rotor magnetic flux given by equation (5) and its position given by equations (5) and (6) depends on $\tau_{r}$ which in turn depends on $R_{r}$. The rotor resistance $R_{r}$ is temperature sensitive. If the temperature varies greatly the estimation of the rotor 
flux and its position will be impaired. This may affect the performance of the control by rotor flow orientation. But if the rotor temperature is known, it will be possible to estimate its resistance, thus correcting the flow estimations.

\subsection{Energizing and Transmitting}

The challenges for placing sensors in the rotor are basically two, energizing the transducer/sensor and transmitting data. With the rotation, the options found to solve these problems are:

- Wireless energizing:

○ Batteries [11][12][13][20];

○ Collector rings;

- RFID (Radio Frequency Identification) [27];

- SAW (Surface Acoustic Wave) [4];

- WPT (Wireless Power Transfer) [15].

- Wireless data transmission:

- RF (Radio Frequency);

- $2.4 \mathrm{GHz}[4][11][12][20] ;$

- $433 \mathrm{MHz}[32]$.

- RFID (Radio Frequency Identification) [27];

- SAW (Surface Acoustic Wave) [4];

$\circ \quad \operatorname{IrDA}$ (Infrared Data Association) [13][18].

Energy harvesting $(\mathrm{EH})$ technology could play a significant role. Harvesting various sources of ambient energy such as vibration, eletromagnetic, thermal and etc. by $\mathrm{EH}$ can be used to power the network nodes while storing the surplus in storage units (e.g, batteries, hypercapacitor) [3][7][26][28][31].

The objective of this work is to develop a wireless embedded system for monitoring the physical variables of the rotor of electric machines. For this, the works were divided in two parts:

1. Design and develop a circuit for reading rotor variables and wireless information transmission.

Following with the study of the effect of the magnetic field of the motor and analysis of packet losses in the wireless transmission.

2. Design and develop a device responsible for harvesting energy from magnetic energy of the rotating field into electrical energy, which will energize the circuit of the embedded system. The device consists of a magnetic generator responsible for capturing magnetic energy, a rectification and regulation stage and an energy storage module using hypercapacitor.

\section{Proposed System Overview}

As previously mentioned, the objective of this work is to develop an embedded system to monitor physical variables an induction motor rotor.

Embedded system can be characterized as combining the use of hardware and software in a device with a predefined purpose. The embedded system has the purpose of controlling processes, or acting on a problem. This is done using the peripherals, which are chosen and sized based on the problem [2][17][30].

The proposed system represented by the block diagram in Figure 1 is formed by an energy generating device and a hardware. The hardware is divided into two printed circuit boards, one to house the data acquisition and communication circuit and one to the power circuit. 


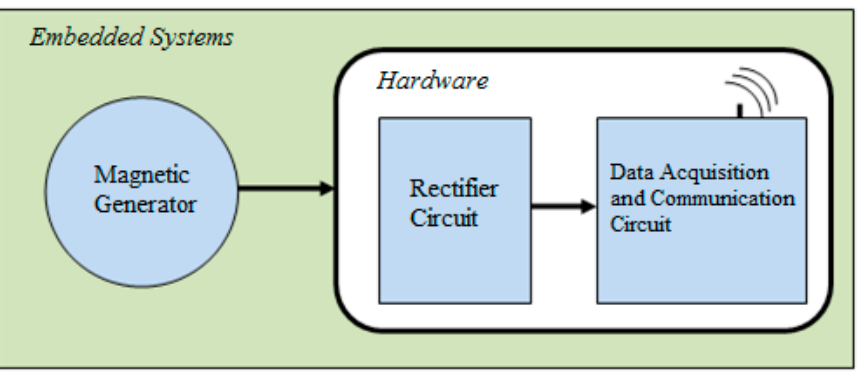

Figure 1.Embedded System Block Diagram

\subsection{Data Acquisition And Communication Circuit.}

The data acquisition and communication circuit has the structure defined in the block diagram shown in Figure 2. It consists basically of transducers, microcontroller and RF module. The microcontroller is responsible for performing the sensors readings, handling the information read and sending them to the RF (Radio Frequency) module. This transmits the rotor temperature values to a computer that can use them for monitoring and/or control.

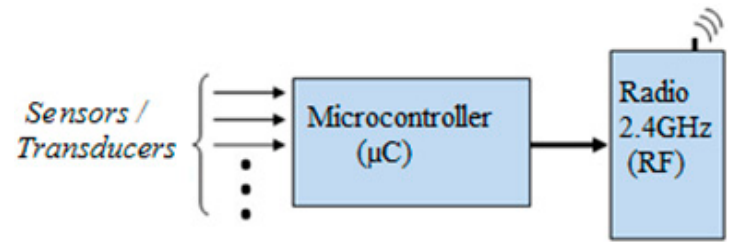

Figure 2. Block diagram of the data acquisition and communication circuit.

\subsection{Power Circuit}

To design the supply circuit and the generating device it is necessary to know the current demand of the load, that is, the acquisition and communication board. From information of the components of this, a maximum expected consumption of approximately $33 \mathrm{~mA}$ was reached, as shown in Table 1.

TABLE 1.Maximum expected current for the PCB of acquisition and communication of data.

\begin{tabular}{cc}
\hline Component & Maximum Current \\
\hline NRF24L01 (Módulo RF) & $14 \mathrm{~mA}$ \\
PIC18F14K50 (Microcontrolador) & $12 \mathrm{~mA}$ \\
DS18b20 (Transdutor) & $4 \mathrm{~mA}$ \\
LED & $3 \mathrm{~mA}$ \\
TOTAL & $-3 \mathrm{~mA}$ \\
\hline
\end{tabular}

With this, it was decided to design a power circuit with output voltage of $3.3 \mathrm{~V}$ and capacity for a maximum current of $50 \mathrm{~mA}$, leaving a margin to avoid overload.

\subsection{Generator Device}

The engine on which the embedded system was installed is a three-phase four-pole squirrel-cage rotor whose nominal parameters are listed in Table 2. From the characteristics of this engine will be dimensioned the generator device of the embedded system.

TABLE 2.Motor Parameters. 


$\begin{array}{cc}\text { Power } & 5.0 \mathrm{HP} \\ \text { Voltage }(\Delta / \mathrm{Y}) & 220 / 380 \mathrm{~V} \\ \text { Current }(\Delta / \mathrm{Y}) & 14.1 / 8.19 \mathrm{~A} \\ \text { Speed } & 1725 \mathrm{RPM} \\ \text { Frequency } & 60 \mathrm{~Hz}\end{array}$

\subsubsection{Math Analysis}

In order to make a qualitative analysis about the parameters and how they influence the induced voltage, a mathematical equation will be developed based on the basic concepts of electromagnetism.

Figures 3. a) and b) illustrate the 4-pole magnetic field within the motor at a given time point, and how the coils of the generating device interact with this magnetic field.

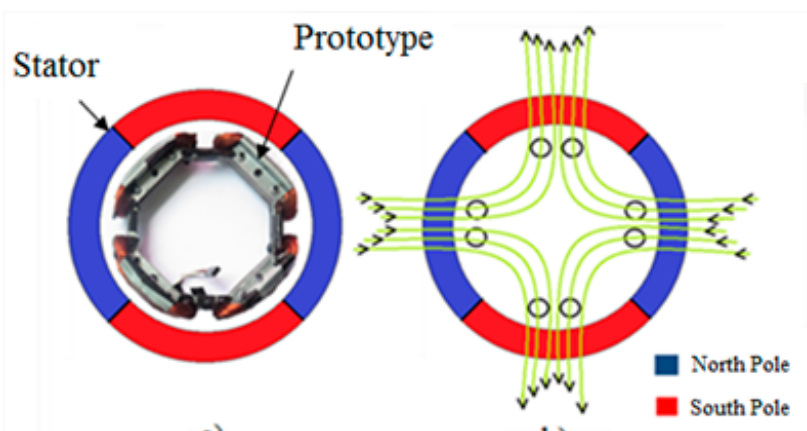

a)

b)

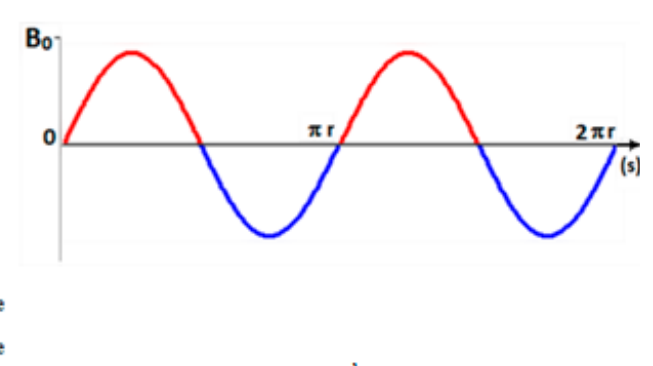

c)

Figure 3. Arrangement of the generator coils in relation to the four poles generated by the stator. a) physical device. b) simplified representation. c) Stator magnetic flow wave form.

The spinning field traverses the coils of the generator with velocity $v$, which in a time interval $\Delta \mathrm{t}$ travels the space $S$. Figure 4.a) shows a top view of Figure 4.b), the small circles in b) are the tips of the magnetic flux arrows in a).

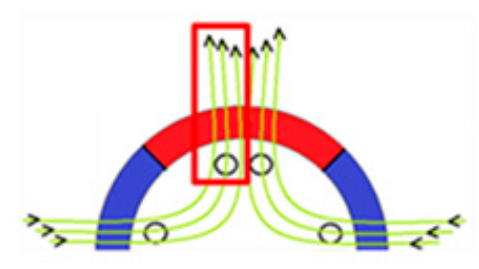

a)

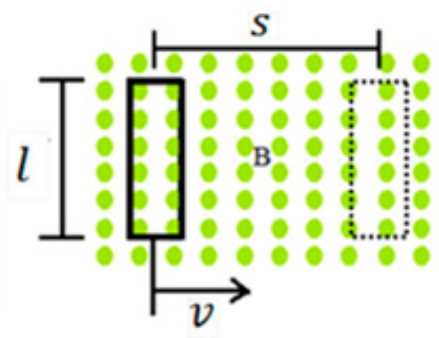

b)

Figure 4. Representation of the relative displacement between coil conductors and the stator magnetic field. a) Fontal view. b) Top view.

Faraday's law states that in a conductor subjected to a magnetic flux variation $\phi$ an induced electromotive force arises $e_{i n d}$ whose absolute value for $N$ conductors is given by:

$$
e_{\text {ind }}=N \frac{d \phi}{d t}
$$

Considering that the magnetic flux is perpendicular to the area swept by the conductor, it can be calculated by:

$$
\phi=\int B d A
$$


6 of 11

The flux density $B$ in the air gap, shown in Figure 3. c), can be described approximately by a sinusoid:

$$
B(s)=B_{0} \operatorname{sen}\left(\frac{2}{r} s\right)
$$

Where $B_{0}$ is the maximum value assumed by $B(s), r$ is the radius of the generator and $s$ is the space traveled along the circumference.

The area can be calculated by:

$$
A(s)=l . s \Rightarrow d A=l d s
$$

Since 1 is the length of the conductor cutting the flow lines, see Figure $4 \mathrm{~b}$ ).

Substituting (10) and (9) into (8), determine the magnetic flux:

$$
\phi(s)=B_{0} l \int_{0}^{s} \operatorname{sen}\left(\frac{2}{r} s\right) d s=\frac{B_{0} l r}{2}\left[1-\cos \left(\frac{2}{r} s\right)\right]
$$

Knowing that,

$$
s=v . t \text { e } v=\frac{\omega}{2} r
$$

In which $v$ and $\omega$ are the linear and angular velocities of the conductor relative to the magnetic flux lines. If the rotor is rotating $\omega$ will be the slip frequency. The value 2 dividing $\omega$ refers to the number of pole pairs.

The expression of the flow becomes:

$$
\phi(t)=\frac{B_{0} l r}{2}[1-\cos (\omega t)]
$$

Substituting (13) into (7) and solving the derivative, we have:

$$
e_{\text {ind }}=\frac{N B_{0} l r \omega}{2} \sin (\omega t)
$$

This equation calculates the induced emf in the conductors of one side of the coil, the emf induced in the complete coil is twice this value, therefore:

$$
e_{\text {ind }}=N B_{0} \operatorname{lr} \omega \sin (\omega t)
$$

This expression reveals that the maximum value of the force depends directly on the dimensions of the generator 1 and $r$, the number of turns that is limited by the dimensions, the slip frequency $\omega$ and $B_{0}$ which is associated with the motor supply current.

\subsubsection{Prototype Construction}

The rotor has a diameter of $99.0 \mathrm{~mm}$, so that a core diameter of $96.0 \mathrm{~mm}$ was defined for the generator core in order to avoid collisions with the stator. The generator device core will be laminated to minimize eddy current losses [6][10][12]. The embedded system will be fixed to the rotor, more specifically to the extensions of the aluminum bars shown in Figure 5.

The blades were made with galvanized steel sheet number 22, material chosen for being ferromagnetic and easily accessible. Each blade is $0.80 \mathrm{~mm}$ thick. Twelve blades were made which, after being ready, received a layer of varnish to electrically isolate one blade from the other. The thickness of the core was approximately $10.0 \mathrm{~mm}$, so as not to compromise the total available space that is $30.0 \mathrm{~mm}$, because there will remain $20.0 \mathrm{~mm}$ for the coils, $10.0 \mathrm{~mm}$ for each side of the core.

Using 30 AWG enameled wire, 4 coils of 180 turns each were connected in series. Figure 5 shows the prototype ready. 


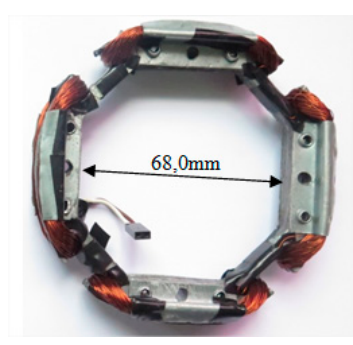

Figure 5. Prototype generator set.

\subsubsection{PCBs Prototyping}

After the circuits were designed the two PCBs were made, the power supply and the acquisition and communication of data. Figure 6 . They are attached through terminals that also connect them electrically. This configuration makes the system more versatile, since if it is necessary to change the acquisition and communication circuit for another one with more sensors or that has some modifications, just replace the corresponding plate. Figure 7 shows the assembled system with all its parts ready.

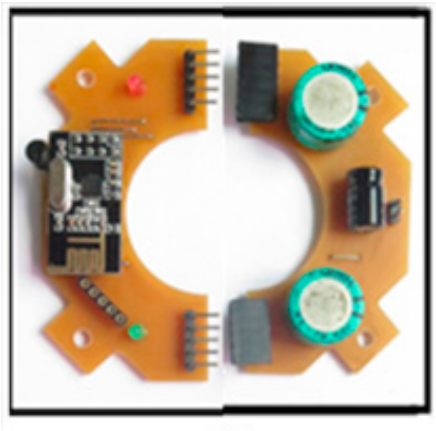

a)

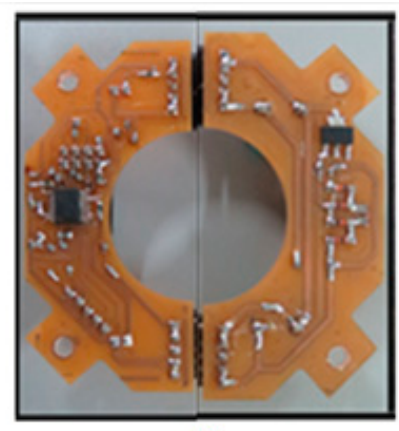

b)

Figure 6. PCBs. a) Top view. b) Bottom view.

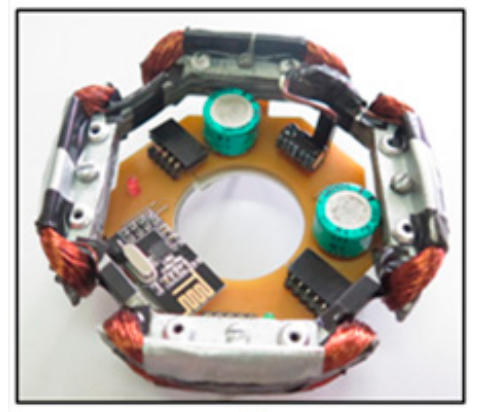

a)

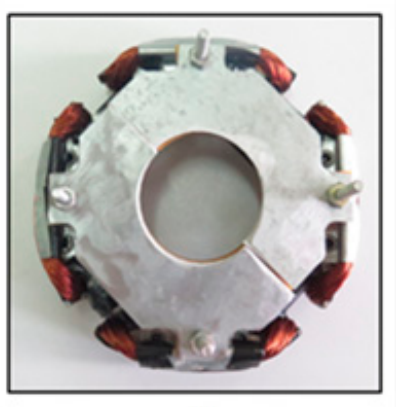

b)

Figure 7. PCBs set on generator device.

\subsubsection{Assembly}

With the generator built and the circuits designed, the PCIs of the rectifier circuit and the data acquisition and communication circuit were made. The parts were joined and the whole system was coupled to the rotor, as shown in Figure 8. 


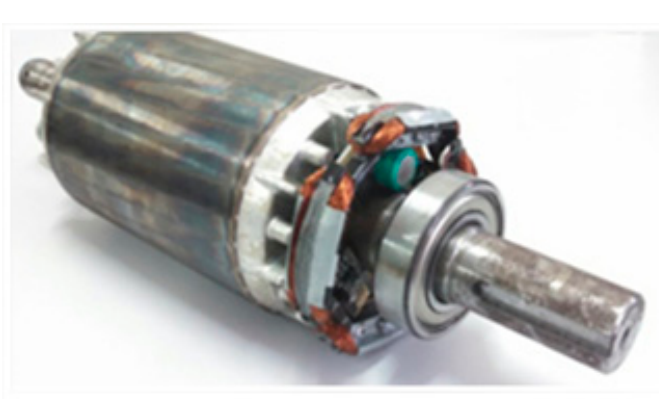

a)

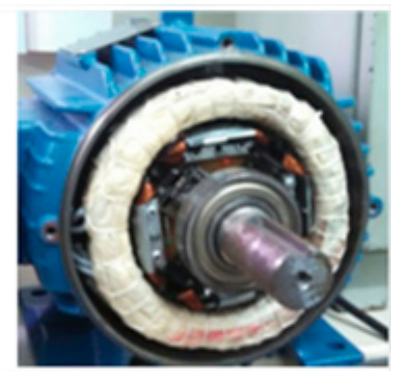

b)

Figure 8. System coupled to the rotor. (A) Outside the stator. (B) Inside the stator.

\section{Results}

All the evaluation tests performed so far have been done without the presence of the rotor, in order to make a previous analysis of the system behavior. Without the rotor the motor can not receive the nominal voltage at its terminals, since the inductance is much smaller, consequently it presents a low impedance which would lead to high current values.

To circumvent the problem a VARIAC was used, with it applied a voltage value necessary to generate the nominal current of the motor.

\subsection{Generator Rating}

The generator device underwent a test to verify if it meets the required voltage and output Power. For that a load of $35 \Omega$ corresponding to the internal resistance of the generator was applied, according to the maximum power transfer theorem, it is in this condition that The generator will provide its maximum power.

During the test a peak voltage of 6 volts $(4.24 \mathrm{Vrms})$ was measured at the output, which corresponds to a power of approximately $500 \mathrm{~mW}$. It required at least $5.5 \mathrm{~V}$ peak and a minimum power of $165 \mathrm{~mW}$. Test shown on Figure 9.
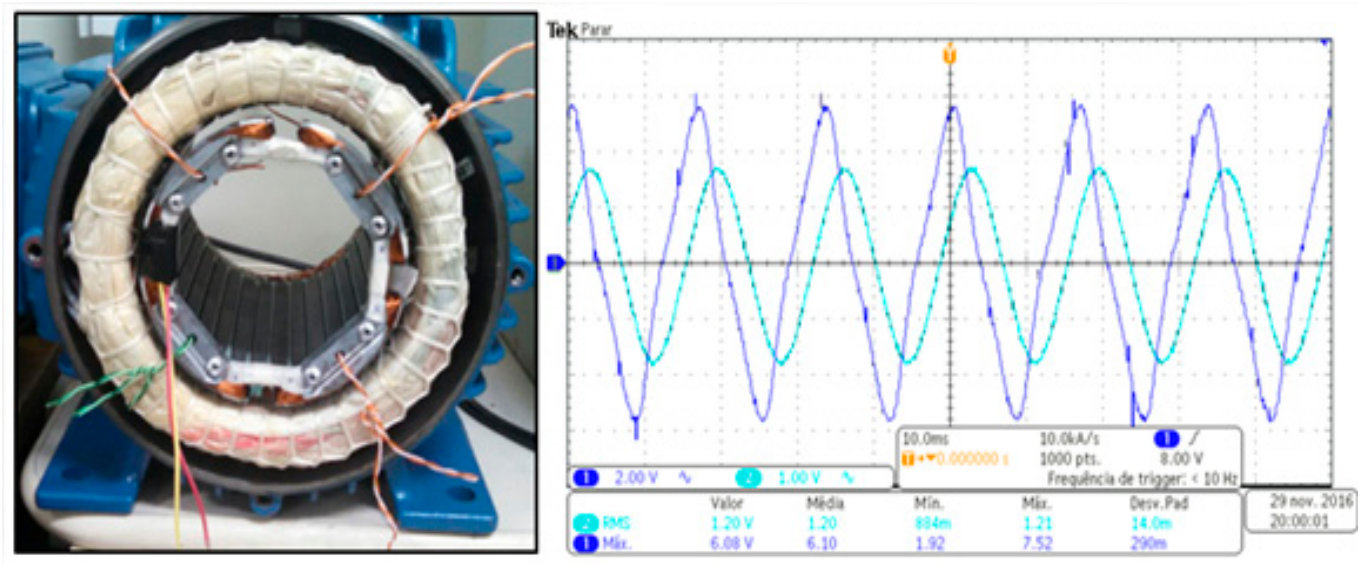

Figure 9. Waveform showing the voltage generated in the generator device.

The next test relied on the embedded system being used as a load, meaning all components being powered by the device. The result can be seen in figure 10. Here the oscilloscope display shows the voltage value at the regulator output. In this test all components are working as, the temperature sensor, the microcontroller and the RF module. Even with the temperature information being sent to a computer on which it is being plotted on a chart, figure 10. 

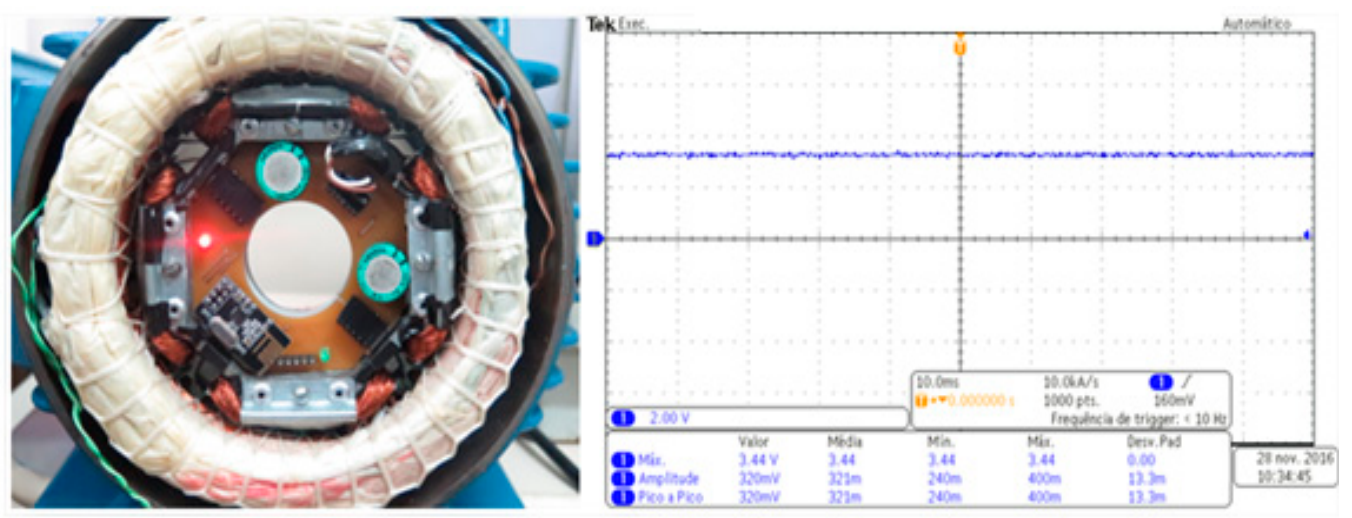

Figure 10. Voltage value generated after passing through the regulator.

\subsection{Evaluation of Data Transmission}

The temperature reading, with the transducer in contact with the generator core, is sent to the PC with a sampling rate of one second. The peaks recorded in the graph were produced by approaching the sensor with a heated soldering iron.

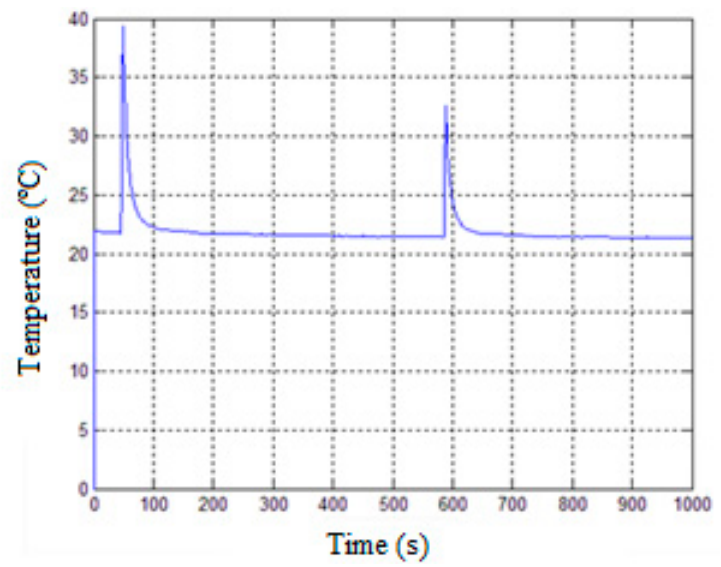

Figure 11. Temperature values, outside the motor, received and plotted on the computer.

In another test to verify the data acquisition and communication circuit, the embedded system was confined inside the engine after the rear and front covers were placed for interference analysis. Figure 12 shows the temperature values read for 1000 seconds. The graph shows the increase in engine temperature due to decreased ventilation.

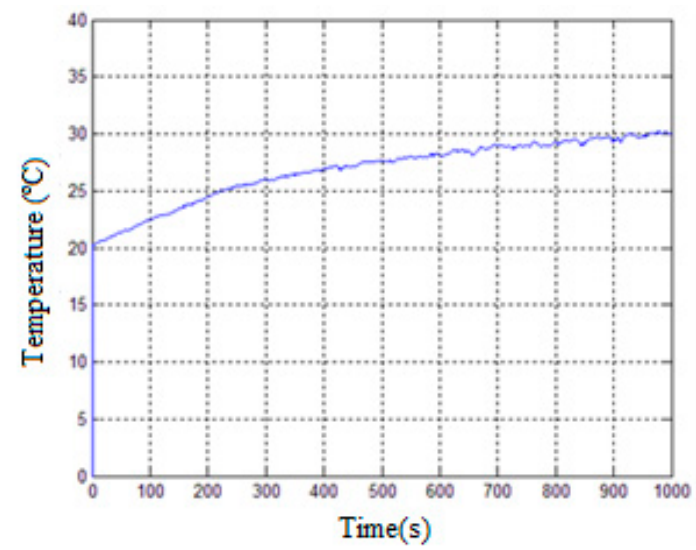

Figure 12. Temperature values, inside the motor, received and plotted on the computer. 
10 of 11

\section{Conclusions}

Although this work has focused on monitoring the rotor temperature of an induction machine, other variables can also be addressed, for example: magnetic field, vibrations, speed.

Another very relevant aspect of this research is the possibility of endowing the embedded system with energy self-sufficiency, which entails less cost with maintenance for battery replacement. Preliminary tests have proved that it is possible to capture electrical energy from the machine's own magnetic field by means of a low-cost solution.

It is possible that for more realistic tests, for example, when the embedded system is rotating coupled to the rotor, that the energy captured is not enough to feed the system, since the induced emf depends on the frequency of slip and this for the nominal rotation of the machine is small. However, it is also possible to perfect the prototype, mainly the power circuit with reduction of the voltage drop in the diodes and reduction in current consumption. It is worth remembering that the prototype in the preliminary tests generated three times the desired maximum power, which in turn was more than $20 \%$ greater than the required.

More important than the prototype is the idea of harnessing the magnetic field of the machine to generate power and power the instrumentation circuits for various purposes. This allows high value machines equipped with several sensors / transducers for variable supervision, control or predictive maintenance, come from the factory with special rotors that in addition to producing torque also generate power to energize your instrument.

\section{References}

1. Al-Ali, S.; Dabbousi, R. Rotor hot spot detection and resolution in large oil and gas industry motors. In: Industry Applications Society Annual Petroleum and Chemical Industry Conference, 60, 2013, Chicago, IL. Anais... Chicago.

2. Andrade, F. S. Sistemas Embarcados, 2. ed. São Paulo: Editora Érica, 2010.

3. Baghaee, S. et al. Towards a vibration energy harvesting WSN demonstration test bed. In: Tyrrhenian International Workshop on Digital Communications - Green ICT (TIWDC), 24, 2013, Genoa. Anais... Genoa. p. 1-6.

4. Binder, A.; Fachberger, R. Wireless SAW Temperature Sensor System for High-Speed High-Voltage Motors.IEEE Sensors Journal, v. 11, n. 4, p. 966-970, Abril 2011.

5. Azevedo, C. C.; Jacobina,C. B.; Ribeiro, L. A. S.; Lima, A. M. N. and Oliveira, A. C. Indirect field orientation for induction motors without speed sensor. Applied Power Electronics Conference and Exposition (APEC), Seventeenth Annual IEEE, Dallas, USA, 2002.

6. Chapman, J. S. Electric Machinery Fundamentals. 4. ed. Columbus: McGraw-Hill, 2005.

7. Deepti; sharma, S. Piezoelectric energy harvesting and management in WSN using MPPT algorithm. In: International Conference on Wireless Communications, Signal Processing and Networking (WiSPNET), 2016, Chennai. Anais... Chennai. p. 2228-2232.

8. Bim , E. “Máquinas Elétricas e Acionamentos”, Elsevier, 3 Edição, ISMB: 978-85-352-7713-5, 2014.

9. Epri, Electric Motor Tiered Maintenance Program. Electric Power Research Institute. Palo Alto, CA, 2002.

10. Fitzgerald, A. E.; kingsley, C. J.; Umans, S. D. Electric Machinery. 6. ed. New York: McGraw-Hill, 2003.

11. Fruth, B. et al. Integrated remote insulation condition monitoring of generators and motors using traditional and wireless sensor technologies. In: International Conference on Computer, Communications, and Control Technology (I4CT), 2014, Langkawi. Anais... Langkawi.

12. Floriduz, A. et al. Wireless temperature sensing in electrical motors with XBee modules. In: IEEE Workshop on Electrical Machines Design, Control and Diagnosis (WEMDCD), 2015, Torino. Anais... Torino.

13. Ganchev, M.; Umschaden, H.; Kappeler, H. Rotor temperature distribution measuring system. Annual Conference on IEEE Industrial Electronics Society - IECON, 37, 2011, Melbourne.Anais... Melborne.

14. Glover, L. D.; Sarma M. S.; Overbye T. J. Power System Analisis\&Desing, 4. ed. Boston: PWS Publishing Company, 2008. 
15. Guo, H.; Ruan, L. Design of wireless powered RF temperature monitoring system applied to the rotor of generators. In: International Conference on Electrical Machines and Systems (ICEMS), 2011, Beijing. Anais... Beijing.

16. Heath, S. Embedded System Design, 2. ed. Oxford: Newnes, 2003.

17. Hudon, C. et al. Rotor temperature monitoring using fiber Bragg gratings.In:IEEE Electrical Insulation Conference (EIC), 2016, Montreal. Anais... Montreal.

18. Kovačić, M.; Vražić, M.; Gašparac, I. Bluetooth wireless communication and 1-wire digital temperature sensors in synchronous machine rotor temperature measurement. In: International Power Electronics and Motion Control Conference (EPE/PEMC), 14, 2010, Ohrid.Anais... Ohrid.

19. Moreira, L, F, S. Otimização da manutenção em plataformas offshore de exploração e produção de petróleo. 2013. 49f. Monografia (Graduação) - Escola Politécnica, Universidade Federal do Rio de Janeiro, Rio de Janeiro.

20. Popov, N.; Vukosavic, S. N. Estimator of the Rotor Temperature of Induction Machines Based on Terminal Voltages and Currents. IEEE Transactions on Energy Conversion, v.PP, n.99, p.1-1, 2016.

21. Roscoe, N. M.; Judd, M. D. Harvesting Energy: From Magnetic Fields to Power Condition Monitoring Sensors. IEEE Sensors Journal, v. 13, n. 6, p. 2263-2270, Jun 2013.

22. Solar et al. A robust, $-40^{\circ}$ to $+150^{\circ} \mathrm{C}$ wireless rotor temperature monitoring system based on a fully passive UHF RFID sensor tag. In: IEEE MTT-S International Microwave Symposium (IMS2014), 2014, Tampa. Anais... Tampa.

23. Sukumaran, S. K.; Purushothaman, M. An approach in energy harvesting from fitness equipment. In: International Conference on Science Engineering and Management Research (ICSEMR), 2014, Chennai. Anais... Chennai, p. 1-5.

24. Jain ,V. Simulation and Modeling of Feedback Field Oriented Control of Asynchronous Machines. IEEE International Conference on Recent Advances and Innovations in Engineering (ICRAIE-2014), Jaipur India, May 09-11, 2014.

25. Vahid, F.; Givardis, T. D. Embedded System Design: A Unified Hardware/Software Introduction. New Jersey: John Wiley\& Sons, 2001.

26. Yuan, S. et al. A High Efficiency Helical Core for Magnetic Field Energy Harvesting. IEEE Transactions on Power Electronics, v.PP, n.99, p.1-1, Set 2016. 